\title{
Changes of Locoregional Skin Temperature in Neonates Undergoing Laser Needle Acupuncture at the Acupuncture Point Large Intestine 4
}

\author{
Stefan Kurath-Koller, ${ }^{1}$ Gerhard Litscher, ${ }^{2}$ Anna Gross, ${ }^{1}$ Thomas Freidl, ${ }^{1}$ \\ Martin Koestenberger, ${ }^{3}$ Berndt Urlesberger, ${ }^{1,4}$ and Wolfgang Raith ${ }^{1,4}$

\begin{abstract}
${ }^{1}$ Division of Neonatology, Department of Paediatrics and Adolescent Medicine, Medical University of Graz, 8036 Graz, Austria
${ }^{2}$ Research Unit for Complementary and Integrative Laser Medicine, Research Unit of Biomedical Engineering in Anesthesia and Intensive Care Medicine and TCM Research Center Graz, Medical University of Graz, 8036 Graz, Austria

${ }^{3}$ Division of Pediatric Cardiology, Department of Paediatrics and Adolescent Medicine, Medical University of Graz, 8036 Graz, Austria ${ }^{4}$ Research Group for Paediatric Traditional Chinese Medicine, TCM Research Center Graz, Medical University of Graz, 8036 Graz, Austria
\end{abstract}

Correspondence should be addressed to Stefan Kurath-Koller; stefan.kurath@medunigraz.at and Gerhard Litscher; gerhard.litscher@medunigraz.at

Received 9 December 2014; Accepted 6 March 2015

Academic Editor: Alessandra Guerrini

Copyright (C) 2015 Stefan Kurath-Koller et al. This is an open access article distributed under the Creative Commons Attribution License, which permits unrestricted use, distribution, and reproduction in any medium, provided the original work is properly cited.

\begin{abstract}
Laser acupuncture bears a potential risk for the skin surface, especially in neonates whose skin has histological and physiological peculiarities. We evaluated thermal changes of skin temperature in neonates during laser acupuncture by using a thermal camera (Flir i5, Flir Systems Inc., Portland, USA). Laserneedles (Laserneedle GmbH, Glienicke/Nordbahn, Germany) were fixed to the skin at Large Intestine 4 (LI 4, Hegu), bilaterally. Before application of laser acupuncture ( $685 \mathrm{~nm}, 15 \mathrm{~mW}, 500 \mu \mathrm{m})$, as well as after 1, 5, and $10 \mathrm{~min}$, thermographic pictures of both hands were taken. The measuring was carried out on the 23rd day after birth (20 neonates, mean postmenstrual gestational age $38+2$, mean weight $2604 \mathrm{~g}$ ). Compared to the initial temperature of $34.2^{\circ} \mathrm{C}$ on the right hand, the skin temperature had increased to $35.3^{\circ} \mathrm{C}(P<0.05)$ after $5 \mathrm{~min}$ and up to $36.1^{\circ} \mathrm{C}(P<0.05)$ after $10 \mathrm{~min}$ of stimulation. Equally, on the left hand, an increase of the skin temperature from $34.5^{\circ} \mathrm{C}$ to $35.9^{\circ} \mathrm{C}(P<0.05)$ and $35.9^{\circ} \mathrm{C}(P<0.05)$ was measured. The highest measured skin temperature after $10 \mathrm{~min}$ of stimulation amounted to $38.7^{\circ} \mathrm{C}$, without any clinically visible changes on the skin surface.
\end{abstract}

\section{Introduction}

Traditional Chinese medicine (TCM) is reported as one of the most popular treatments for children [1]. TCM includes (i) massage therapy (Tuina), (ii) moxibustion, and (iii) different kinds of acupuncture and acupressure [2]. The most common additional applications for acupuncture in the pediatric population are from the area of pediatric oncology [3-5] suggesting that acupuncture is an appropriate adjunctive treatment for chemotherapy-induced nausea/vomiting [6] and for different kinds of pain [7-9]. In addition, both a recent and a 3-year-old systematic review of acupuncture for children and newborns found that acupuncture is a safe treatment when performed by trained and licensed acupuncturists $[10,11]$. Both therapy and prevention of pain $[12]$ are warranted to avoid acute physiologic reactions [13] and there are data that pain-related stress can induce long-term effects, like poorer cognition and motor functions, as well as lead to altered cortisol levels in patients at school age $[14,15]$. The limited data available suggests that needle acupuncture is a safe nonpharmacologic treatment option for the reduction of pain $[16,17]$ and agitation in term and preterm infants 
$[11,18,19]$ and in the therapy of infantile colic [20-24]. But at the moment it is unknown whether repeated needle stimulation may alter sensory processing and responses to subsequent painful stimuli, in the same manner like heel sticks used on infants $[13,14]$. Therefore, most acupuncturists who treat children use special techniques, including nonneedle methods, (e.g., lasers and vigorous massage or tapping) to stimulate points along the energy meridians. The development of laser acupuncture [25] has opened a new door in the treatment of children and is continuing to do so. The result is a noninvasive therapeutic approach which, additionally, rules out any existing risks of infection [11, 25, 26]. At the moment there are a few trials [27-30] and a few case series promising positive results in laser acupuncture treatment for children [31-33] and in neonates with neonatal abstinence syndrome (NAS) [34, 35]. Furthermore, in vitro experiments demonstrated that irradiation with red laser light of $657 \mathrm{~nm}$ stimulates adenosine triphosphate (ATP) release [36] which is associated with an intracellular free $\mathrm{Ca} 2+$ rise in human mast cells, similar to needle acupuncture [25]. However laser acupuncture has to be used with caution bearing a potential risk for eyes and skin surface. The neonatal skin is thinner and represents a much more sensitive barrier than the skin of adults [37], putting it at risk for potential thermal damage. There has, however, only been very little literature about laser acupuncture in neonates dealing with peripheral and central changes $[38,39]$ and clear recommendations are still missing [40-42]. Therefore, the aim of this study was to evaluate thermal changes of skin temperature in neonates by the use of an infrared thermal camera to get more data about the safety for the use of laser acupuncture in this vulnerable population.

\section{Materials and Methods}

2.1. Probands. The probands were former premature infants hospitalized at the Division of Neonatology, Department of Paediatrics and Adolescent Medicine at the Medical University Graz who were all tested in the sleep lab before being discharged from hospital. Their parents were informed about the examination and gave their prior written consent. The study itself was submitted to the Ethics Committee of the Medical University of Graz and approved.

All together 20 neonates (12 male, 8 female, mean gestational age (GA) [43] $35+0$ weeks of pregnancy, and mean birth weight $2261.2 \mathrm{~g}$ ) were included in the study. On average, the measuring was carried out on the 23rd day after birth (chronological age) with a mean postmenstrual GA $38+2$ weeks of pregnancy [43] and a mean weight of $2604 \mathrm{~g}$ at the time of examination.

Table 1 gives data of the children involved in the study.

2.2. Laser Acupuncture. The laserneedle used for acupuncture (Laserneedle GmbH, Glienicke/Nordbahn, Germany) provides continuous laser light with a wavelength of $685 \mathrm{~nm}$ and an output power of $15 \mathrm{~mW}$ per laserneedle. The diameter of the laserneedle is $500 \mu \mathrm{m}$.
TABLE 1: Demographic data of the 20 participants of the study. Values are mean and standard deviation for continuous data and absolute counts for categorical data.

\begin{tabular}{lc}
\hline Investigated neonates & $N=20$ \\
\hline Male/female) & $(12 / 8)$ \\
Mean GA* & $35+0$ \\
Mean birth weight & $2261.2 \mathrm{~g}(\mathrm{SD}=909.2)$ \\
Mean arterial PH from umbilical cord & $7.28(\mathrm{SD}=0.09)$ \\
sampling & $7.5(\mathrm{SD}=1.9)$ \\
Mean APGAR 1 & $8.5(\mathrm{SD}=1.39)$ \\
Mean APGAR 5 & $8.9(\mathrm{SD}=1.08)$ \\
Mean APGAR 10 & $38+2$ \\
Mean postmenstrual GA* ${ }^{*}$ at the time of & \\
investigation & $23(\mathrm{SD}=15)$ \\
Mean chronological age, at the time of & \\
investigation & $2604 \mathrm{~g}(\mathrm{SD}=611.7)$ \\
Mean weight, at the time of investigation
\end{tabular}

${ }^{*} \mathrm{GA}$ : gestational age in completed weeks [43].

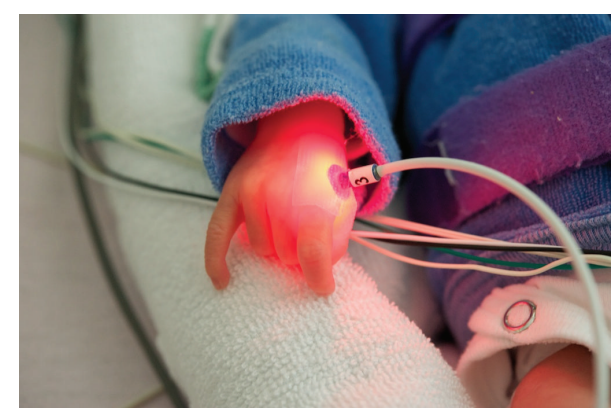

FIGURE 1: Demonstration of the applied laserneedle at the acupuncture point Large Intestine 4 (LI 4, Hegu).

2.3. Procedure. The probands were comfortably placed in a Babytherm 8000 incubator (Dräger GmbH, Lübeck, Germany) in the course of the sleep lab examination. In all incidents, a time period of $10 \mathrm{~min}$ of waiting was respected before applying the laserneedles to give the skin of the neonates a chance to acclimatize to the temperature. Before laser acupuncture was performed, the skin at the acupuncture point was disinfected and the laserneedles were fixed to the skin with a special adhesive tape, bilaterally at Large Intestine 4 (LI 4, Hegu) (Figure 1).

Then, after a waiting period of 25 minutes, after applying the laserneedles, laserneedle acupuncture was performed simultaneously on both arms at the LI 4 (Hegu) point. The first stimulation lasted for $5 \mathrm{~min}$. After an interval of 10 minutes, a second stimulation was carried out in the same way but this time lasting for 10 minutes.

\subsection{Acupuncture Point}

Large Intestine 4 (LI4, Hegu). LI4 (Hegu) is located on the large intestine meridian, on the dorsum of the hand, between the first and second metacarpal bone on the radial side [42]. 


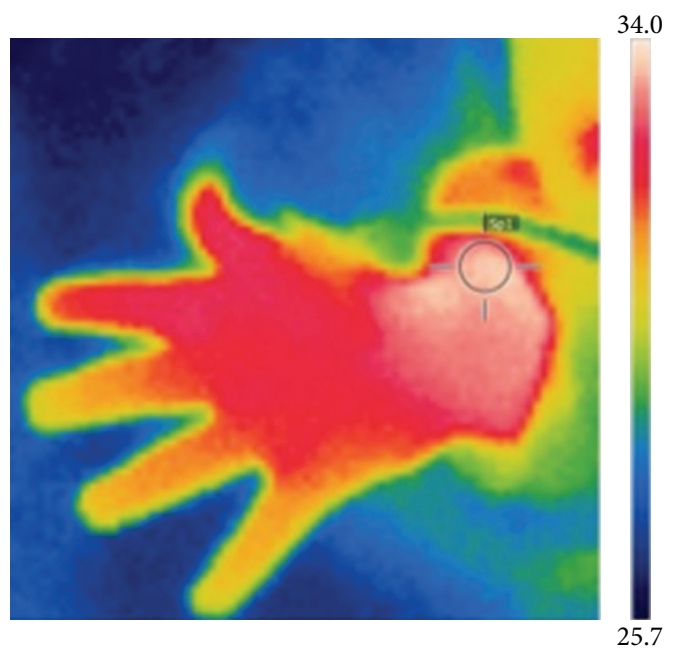

FIGURE 2: An example of the pictures taken with the use of the thermal camera after laserneedle stimulation. Values are presented as ${ }^{\circ} \mathrm{C}$.

2.5. Thermography. Before application of laser acupuncture, as well as after $1 \mathrm{~min}, 5 \mathrm{~min}$, and $10 \mathrm{~min}$, respectively, thermographic pictures of both the left and right hands were taken by means of a thermal camera (Flir i5, Flir Systems Inc., Portland, USA). Subsequently, the warmest spot was identified and reidentified and compared throughout the course of time.

Figure 2 gives an example of the pictures taken with the thermal camera.

Additionally in the course of the examination, any parameters measurable in the context of polygraphy, such as the heart rate, oxygen saturation, end-expiratory $\mathrm{CO}_{2}$, and breathing movements including electroencephalography, were recorded and analyzed. Throughout the examination, the ambient temperature and humidity were kept constant. At that point, in time of the examination, no medication modifying the blood circulation was administered.

2.6. Statistics. All data were taken as a mean value $\pm \mathrm{SD}$ (standard deviation). The statistical evaluation was done using an ANOVA test (Analysis of Variance) for repeated measuring and the Tukey test, respectively (SigmaPlot 12.0, Systat Software, Chicago, USA). The level of significance was defined as $P<0.05$.

2.7. Safety Precautions. The physician carrying out the acupuncture is a general physician and a specialist in pediatric and adolescent medicine as well as in neonatology and intensive care medicine; he also has a diploma in acupuncture and more than 10 years of experience.

The acupuncturist and any other person in the room (e.g., the nurse and the parents) put on specific protective glasses to avoid retinal damage. However, for newborn infants there are no adequate protective glasses available. Therefore the eyes were covered using an eye protector (Natus Biliband Eye Protector, Natus Med. Inc., San Carlos, USA) to avoid any injury to their eyes, as previously described $[38,44]$.

\section{Results}

Altogether, 360 thermographic measurements were taken of the above-mentioned measuring points ( 9 on the right hand and 9 on the left hand of each infant).

Findings on the Right Hand. Compared to the initial temperature of $34.2^{\circ} \mathrm{C}$, the skin temperature had significantly increased to $35.3^{\circ} \mathrm{C}(P<0.05)$ after $5 \mathrm{~min}$ of stimulation. Equally, a significant rise in temperature was measured again after 10 min of stimulation $\left(36.1^{\circ} \mathrm{C}\right)(P<0.05)$. The maximum measured skin temperature after stimulation was found to be $38.3^{\circ} \mathrm{C}$.

Findings on the Left Hand. Compared to the initial temperature of $34.5^{\circ} \mathrm{C}$, the skin temperature had significantly increased to $35.9^{\circ} \mathrm{C}(P<0.05)$ after $5 \mathrm{~min}$ of stimulation. Equally, a significant rise in temperature was measured again after $10 \mathrm{~min}$ of stimulation $\left(35.9^{\circ} \mathrm{C}\right)(P<0.05)$. The maximum measured skin temperature after stimulation was found to be $38.7^{\circ} \mathrm{C}$. Maximum temperatures on the right and left hand were both measured for the same patient.

There was no mention of patient distress or discomfort during laser acupuncture.

The parameters simultaneously measured during the examination (heart rate, oxygen saturation, and end-expiratory $\mathrm{CO}_{2}\left(\mathrm{CO}_{2}\right.$, carbon dioxide $)$ ) and breathing movements including electroencephalography showed no significant changes.

Figures 3(a) and 3(b) display the data of temperature measurements of the right and the left hand.

\section{Discussion}

Thermography, that is, the temperature measured by means of an infrared camera, represents a measuring procedure already used for acupunctural research in adults [45, 46]. Thermography is well established for children [47] and neonates $[48,49]$, because with this method the visualization of temperature distributions of a high local resolution is possible. Furthermore, the diagnostic procedure does not have any radiation-like side effects, is quick to perform, can be repeated as frequently as necessary, and is a noncontact form of examination.

Raith et al. [39] showed that the use of laser acupuncture applied at $10 \mathrm{~mW}$ over a period of 10 minutes, repetitively, does not cause dangerous thermal effects on the neonatal skin. However, the acupuncture effect of laser stimulation depends on the power density at the acupuncture point. Litscher and Schikora [50] hypothesized that a higher energy dosage caused by either higher laser output power or a longer radiation time might result in a more significant increase in skin temperature. Now, comparing our results using the $15 \mathrm{~mW}$ laserneedle stimulation over 5 and 10 minutes, constituting the same radiation time as used in the prior study of Raith et al. [39], and using the $10 \mathrm{~mW}$ laserneedle stimulation, we found the following: a stepwise statistically significant increase in skin temperature either between placebo (the laserneedle fixed at the LI4 acupuncture point without stimulation) and 5-minute laser stimulation or between 5-minute 


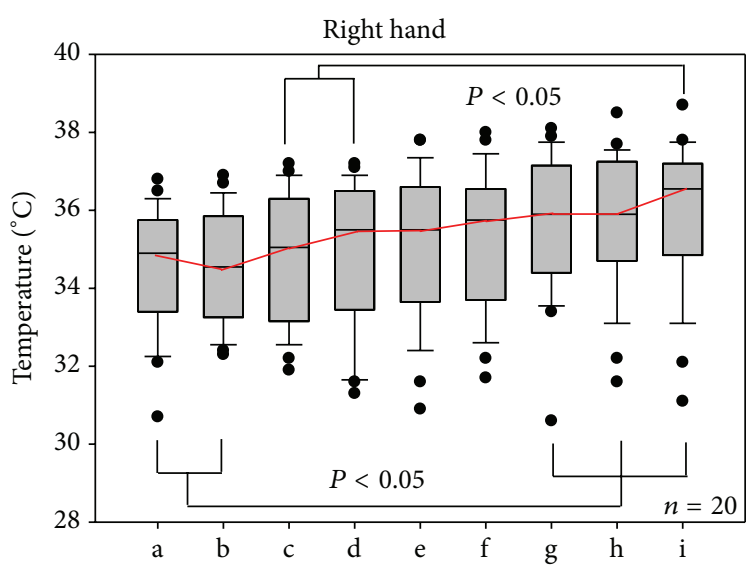

(a)

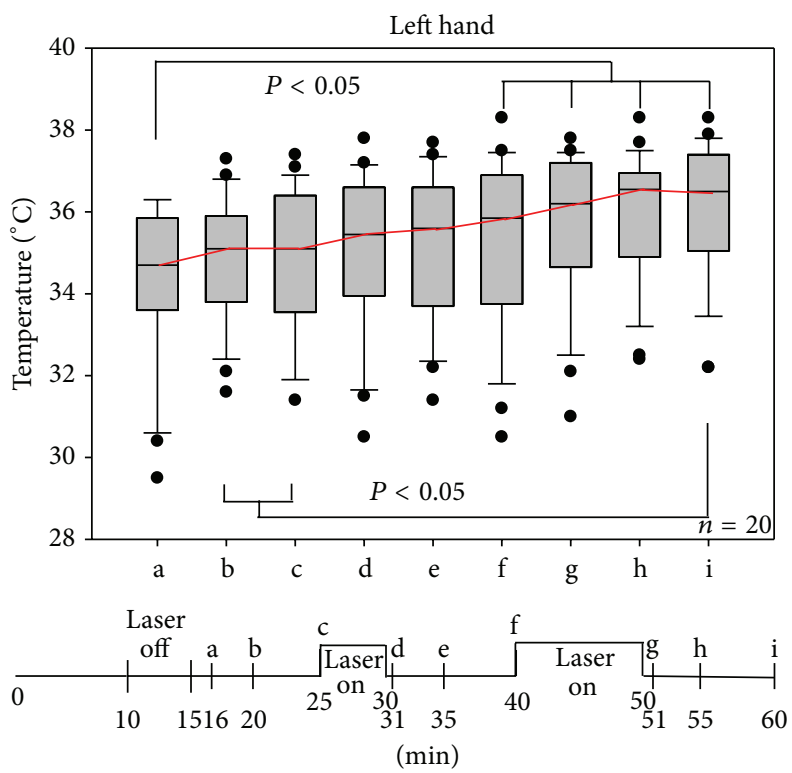

(b)

FIGURE 3: Results and time curve of the examination of the left and the right hand.

and 10-minute laser stimulation was found in both study protocols, using $10 \mathrm{~mW}$ and $15 \mathrm{~mW}$ laserneedle stimulation. However, there was an increase in peak skin temperature of $0.8^{\circ} \mathrm{C}$ comparing our $15 \mathrm{~mW}$ laser stimulation to the prior performed $10 \mathrm{~mW}$ laser stimulation performed by Raith et al. [39] $\left(37.9^{\circ} \mathrm{C}\right.$ using $10 \mathrm{~mW}$ versus $38.7^{\circ} \mathrm{C}$ using $15 \mathrm{~mW}$ ). In both the $10 \mathrm{~mW}$ and the $15 \mathrm{~mW}$ laserneedle stimulation, the peak temperature was measured after the 10-minute stimulation course. However, the warming of the skin after 5 and $10 \mathrm{~min}$, respectively, of laserneedle acupuncture using a laserneedle $(15 \mathrm{~mW} / 685 \mathrm{~nm})$ does not reach such high skin temperature compared to the local temperatures reached in transcutaneous blood gas measuring, as widely used in certain neonatal intensive care units all over Germany, Switzerland, and Austria [51, 52].

Regarding energy dosage we calculated that laser acupuncture applied at $15 \mathrm{~mW}$ over a period of 5 minutes, using a laserneedle with a diameter of $500 \mu \mathrm{m}$, results in an energy dosage of about $2.3 \mathrm{~kJ} / \mathrm{cm}^{2}$ and over 10 minutes in an energy dosage of about $4.6 \mathrm{~kJ} / \mathrm{cm}^{2}$.

We chose LI 4 due to its easy accessibility and because it can be quickly and easily found, being located at the dorsum of the hand. Since examination took place throughout the polysomnography and laserneedles had to be applied, accessibility played an important part in choosing the acupuncture point. Moreover we attempted to select an acupuncture point that is one of the most commonly used acupuncture points especially for newborn infants and children; LI 4 is the most used acupuncture point for the therapy of infantile colic, and current evidence suggests that it is effective and safe $[11,20$, $22,23]$. Further evidence for efficacy and safety comes from observational studies with 913 infants [24] and a case report in an infant suffering from NAS where laser acupuncture at LI
4 was found to positively affect feeding and improve calmness [35].

It has been well established that acupuncture stimulation at LI 4 elicits local microcirculation $[53,54]$ as an indicator of a reduced sympathetic activity $[54,55]$. However, the question as to whether or not changes in the surface temperature in connection with the application of laser acupuncture in neonates are to be understood as changes in the sympathetic activity, and therefore as an effect directly resulting from acupuncture, could not be answered by this study.

\section{Conclusion}

In neonates and infants whose skin is altogether thin and shows physiological and histological peculiarities, it is important to know that there is a potential danger of damage to the skin by using laser acupuncture. In the present study we did not observe any adverse events and the highest measured skin temperature after $10 \mathrm{~min}$ of stimulation amounted to $38.7^{\circ} \mathrm{C}$. No newborn infant developed clinically visible changes on the skin surface due to laser acupuncture, suggesting that laser acupuncture is safe. However the warming of the skin during/after the use of laser acupuncture in neonates and infants should be treated with caution.

Currently acupuncture should be limited to thoroughly monitored clinical trials, and further studies evaluating shortand long-term effects are urgently needed.

\section{Abbreviations \\ TCM: $\quad$ Traditional Chinese medicine \\ ATP: $\quad$ Adenosin triphosphat \\ LI 4 (Hegu): Large Intestine 4 \\ GA: Gestational age}


SD: $\quad$ Standard deviation of the mean

APGAR: Apgar-score

NAS: Neonatal abstinence syndrome.

\section{Conflict of Interests}

The authors have no conflict of interests relevant to this paper to disclose.

\section{Acknowledgment}

The authors thank Evelyn Ziehenberger for her help in realization of the study.

\section{References}

[1] T. J. Zuzak, J. Boňková, D. Careddu et al., "Use of complementary and alternative medicine by children in Europe: published data and expert perspectives," Complementary Therapies in Medicine, vol. 21, no. 1, pp. S34-S47, 2013.

[2] J. Cao, C. Su, and J. Cao, Essentials of Traditional Chinese Pediatrics, Foreign Language Press, Beijing, China, 1990.

[3] V. Jindal, A. Ge, and P. J. Mansky, "Safety and efficacy of acupuncture in children: a review of the evidence," Journal of Pediatric Hematology/Oncology, vol. 30, no. 6, pp. 431-442, 2008.

[4] S. Gottschling, S. Meyer, A. Längler, G. Scharifi, F. Ebinger, and B. Gronwald, "Differences in use of complementary and alternative medicine between children and adolescents with cancer in Germany: a population based survey," Pediatric Blood and Cancer, vol. 61, no. 3, pp. 488-492, 2014.

[5] M. K. Garcia, J. Mcquade, R. Haddad et al., "Systematic review of acupuncture in cancer care:a synthesis of the evidence," Journal of Clinical Oncology, vol. 31, no. 7, pp. 952-960, 2013.

[6] A. Lee and L. T. Fan, "Stimulation of the wrist acupuncture point P6 for preventing postoperative nausea and vomiting," Cochrane Database of Systematic Reviews, no. 2, Article ID CD003281, 2009.

[7] L. Young and K. J. Kemper, "Integrative care for pediatric patients with pain," Journal of Alternative and Complementary Medicine, vol. 19, no. 7, pp. 627-632, 2013.

[8] L. M. Rusy, S. J. Weisman, and K. R. Hainsworth, "Developing an in-patient acupuncture treatment in a pediatric hospital," Journal of Complementary \& Integrative Medicine, 2013.

[9] K. R. Gentry, K. L. McGinn, A. Kundu, and A. M. Lynn, "Acupuncture therapy for infants: a preliminary report on reasons for consultation, feasibility, and tolerability," Paediatric Anaesthesia, vol. 22, no. 7, pp. 690-695, 2012.

[10] D. Adams, F. Cheng, H. Jou, S. Aung, Y. Yasui, and S. Vohra, "The safety of pediatric acupuncture: a systematic review," Pediatrics, vol. 128, no. 6, pp. e1575-e1587, 2011.

[11] W. Raith, B. Urlesberger, and G. M. Schmölzer, "Efficacy and safety of acupuncture in preterm and term infants," EvidenceBased Complementary and Alternative Medicine, vol. 2013, Article ID 739414, 7 pages, 2013.

[12] R. R. P. Riddell, N. M. Racine, K. Turcotte et al., "Nonpharmacological management of infant and young child procedural pain," The Cochrane Database of Systematic Reviews, no. 10, Article ID CD006275, 2011.

[13] R. Carbajal, A. Rousset, C. Danan et al., "Epidemiology and treatment of painful procedures in neonates in intensive care units," The Journal of the American Medical Association, vol. 300, no. 1, pp. 60-70, 2008.

[14] R. E. Grunau, "Neonatal pain in very preterm infants: longterm effects on brain, neurodevelopment and pain reactivity," Rambam Maimonides Medical Journal, vol. 4, no. 4, Article ID $\mathrm{e} 0025,2013$.

[15] S. Brummelte, C. M. Y. Chau, I. L. Cepeda et al., "Cortisol levels in former preterm children at school age are predicted by neonatal procedural pain-related stress," Psychoneuroendocrinology, vol. 51, pp. 151-163, 2015.

[16] B. Golianu, E. Krane, J. Seybold, C. Almgren, and K. J. S. Anand, "Non-pharmacological techniques for pain management in neonates," Seminars in Perinatology, vol. 31, no. 5, pp. 318-322, 2007.

[17] C. C. Yates, A. J. Mitchell, L. M. Lowe, A. Lee, and R. W. Hall, "Safety of noninvasive electrical stimulation of acupuncture points during a routine neonatal heel stick," Medical Acupuncture, vol. 25, no. 4, pp. 285-290, 2013.

[18] A. Ecevit, D. A. Ince, A. Tarcan, M. T. Cabioglu, and A. Kurt, "Acupuncture in preterm babies during minor painful procedures," Journal of Traditional Chinese Medicine, vol. 31, no. 4, pp. 308-310, 2011.

[19] A. C. Filippelli, L. F. White, L. W. Spellman et al., "Non-insertive acupuncture and neonatal abstinence syndrome: a case series from an inner-city safety net hospital," Global Advances in Health and Medicine, vol. 1, no. 4, pp. 48-52, 2012.

[20] K. Landgren, N. Kvorning, and I. Hallström, "Acupuncture reduces crying in infants with infantile colic: a randomised, controlled, blind clinical study," Acupuncture in Medicine, vol. 28, no. 4, pp. 174-179, 2010.

[21] H. Skjeie, T. Skonnord, A. Fetveit, and M. Brekke, "Acupuncture for infantile colic: a blinding-validated, randomized controlled multicentre trial in general practice," Scandinavian Journal of Primary Health Care, vol. 31, no. 4, pp. 190-196, 2013.

[22] K. Landgren, N. Kvorning, and I. Hallström, "Feeding, stooling and sleeping patterns in infants with colic-a randomized controlled trial of minimal acupuncture," BMC Complementary and Alternative Medicine, vol. 11, article 93, 2011.

[23] M. Reinthal, S. Andersson, M. Gustafsson et al., "Effects of minimal acupuncture in children with infantile colic-a prospective, quasi-randomised single blind controlled trial," Acupuncture in Medicine, vol. 26, no. 3, pp. 171-182, 2008.

[24] M. Reinthal, I. Lund, D. Ullman, and T. Lundeberg, "Gastrointestinal symptoms of infantile colic and their change after light needling of acupuncture: a case series study of 913 infants," Chinese Medicine, vol. 6, article 28, 2011.

[25] P. Whittaker, "Laser acupuncture: past, present, and future," Lasers in Medical Science, vol. 19, no. 2, pp. 69-80, 2004.

[26] W. Raith, G. Litscher, W. Müller, and B. Urlesberger, "Laseracupuncture: a possible alternative treatment for agitation and pain in neonates?" Paediatric Anaesthesia, vol. 23, no. 2, pp. 205206, 2013.

[27] J. Zhang, X. Li, J. Xu, and E. Ernst, "Laser acupuncture for the treatment of asthma in children: a systematic review of randomized controlled trials," Journal of Asthma, vol. 49, no. 7, pp. 773-777, 2012.

[28] S. Gottschling, S. Meyer, I. Gribova et al., "Laser acupuncture in children with headache: a double-blind, randomized, bicenter, placebo-controlled trial," Pain, vol. 137, no. 2, pp. 405-412, 2008. 
[29] M. I. Karaman, O. Koca, E. V. Küçük, M. Öztürk, M. Güneş, and C. Kaya, "Laser acupuncture therapy for primary monosymptomatic nocturnal enuresis," Journal of Urology, vol. 185, no. 5, pp. 1852-1856, 2011.

[30] E. Radvanska, K. Kamperis, A. Kleif, L. Kovcs, and S. Rittig, "Effect of laser acupuncture for monosymptomatic nocturnal enuresis on bladder reservoir function and nocturnal urine output," Journal of Urology, vol. 185, no. 5, pp. 1857-1861, 2011.

[31] A. Stellon, "The use of laser acupuncture for the treatment of neurogenic pruritus in a child-a case history," Acupuncture in Medicine, vol. 23, no. 1, pp. 31-33, 2005.

[32] D. Ding, "Treatment of infantile diarrhea by acupuncture and laser irradiation-a report of 60 cases," Journal of Traditional Chinese Medicine, vol. 24, no. 4, pp. 280-281, 2004.

[33] C. R. Fontana and V. S. Bagnato, "Low-level laser therapy in pediatric bell's palsy: case report in a three-year-old child," Journal of Alternative and Complementary Medicine, vol. 19, no. 4, pp. 376-382, 2013.

[34] W. Raith, G. Pichler, H. Zotter, W. Mueller, and B. Urlesberger, "Detection of psychic ear acupuncture points in a newborn infant with neonatal abstinence syndrome," Journal of Alternative and Complementary Medicine, vol. 16, no. 4, pp. 345-346, 2010.

[35] W. Raith and B. Urlesberger, "Laser acupuncture as an adjuvant therapy for a neonate with neonatal abstinence syndrome (NAS) due to maternal substitution therapy: additional value of acupuncture," Acupuncture in Medicine, vol. 32, no. 6, pp. 523$524,2014$.

[36] L. Wang, J. Sikora, L. Hu, X. Shen, R. Grygorczyk, and W. Schwarz, "ATP release from mast cells by physical stimulation: a putative early step in activation of acupuncture points," Evidence-Based Complementary and Alternative Medicine, vol. 2013, Article ID 350949, 7 pages, 2013.

[37] Y. Cousins, "Wound care considerations in neonates," Nursing Standard, vol. 28, no. 46, pp. 61-70, 2014.

[38] W. Raith, G. Pichler, I. Sapetschnig et al., "Near-infrared spectroscopy for objectifying cerebral effects of laser acupuncture in term and preterm neonates," Evidence-Based Complementary and Alternative Medicine, vol. 2013, Article ID 346852, 6 pages, 2013.

[39] W. Raith, G. Litscher, I. Sapetschnig et al., "Thermographical measuring of the skin temperature using laser needle acupuncture in preterm neonates," Evidence-based Complementary and Alternative Medicine, vol. 2012, Article ID 614210, 5 pages, 2012.

[40] P. Pöntinen and R. Pothman, Laser in Acupuncture, Hippokrates, Stuttgart, Germany, 2005.

[41] http://waltza.co.za/wp-content/uploads/2012/08/Dose_table_ 780-860nm_for_Low_Level_Laser_Therapy_WALT-2010.pdf.

[42] M. Loo, Pediatric Acupuncture, Churchill Livingstone, Edinburgh, UK, 2002.

[43] W. A. Engle and American Academy of Pediatrics Committee on Fetus and Newborn, "Age terminology during the perinatal period," Pediatrics, vol. 114, no. 5, pp. 1362-1364, 2004.

[44] W. Raith, G. M. Schmölzer, B. Resch, M. Seewann, W. Müller, and B. Urlesberger, "Laser acupuncture as a possible treatment for an agitated infant-a preterm after 28 weeks of gestation," German Journal of Acupuncture \& Related Techniques, vol. 51, no. 3, pp. 33-36, 2008 (German).

[45] K. Agarwal-Kozlowski, A.-C. Lange, and H. Beck, "Contact-free infrared thermography for assessing effects during acupunc- ture: a randomized, single-blinded, placebo-controlled crossover clinical trial," Anesthesiology, vol. 111, no. 3, pp. 632-639, 2009.

[46] G. Litscher, "Bioengineering assessment of acupuncture, Part 1: thermography," Critical Reviews in Biomedical Engineering, vol. 34, no. 1, pp. 1-22, 2006.

[47] A. K. Saxena and G. H. Willital, "Infrared thermography: experience from a decade of pediatric imaging," European Journal of Pediatrics, vol. 167, no. 7, pp. 757-764, 2008.

[48] R. T. Frankenberger, O. Bussmann, W. Nahm, E. Konecny, and L. Gortner, "Measuring lateral skin temperature profile of premature infants in incubators with thermography," Biomedical Engineering, vol. 43, no. 6, pp. 174-178, 1998.

[49] R. B. Knobel, B. D. Guenther, and H. E. Rice, “Thermoregulation and thermography in neonatal physiology and disease," Biological Research for Nursing, vol. 13, no. 3, pp. 274-282, 2011.

[50] G. Litscher and D. Schikora, Laserneedle-Acupuncture: Science and Practice, Pabst Science, Berlin, Germany, 2005.

[51] M. Rüdiger, K. Töpfer, H. Hammer, G. Schmalisch, and R. R. Wauer, "A survey of transcutaneous blood gas monitoring among European neonatal intensive care units," BMC Pediatrics, vol. 5, article 30, 2005.

[52] C. Domingo, L. Blanch, G. Murias, and M. Luján, "State-ofthe-art sensor technology in spain: invasive and non-invasive techniques for monitoring respiratory variables," Sensors, vol. 10, no. 5, pp. 4655-4674, 2010.

[53] H. Hsiu, W.-C. Hsu, C.-L. Hsu, and S.-M. Huang, "Assessing the effects of acupuncture by comparing needling the hegu acupoint and needling nearby nonacupoints by spectral analysis of microcirculatory laser doppler signals," Evidence-based Complementary and Alternative Medicine, vol. 2011, Article ID 435928, 9 pages, 2011.

[54] S. Min, H. Lee, S. Y. Kim et al., "Local changes in microcirculation and the analgesic effects of acupuncture: a laser doppler perfusion imaging study," Journal of Alternative and Complementary Medicine, vol. 21, no. 1, pp. 46-52, 2014.

[55] M. Ernst and M. H. M. Lee, "Sympathetic vasomotor changes induced by manual and electrical acupuncture of the hoku point visualized by thermography," Pain, vol. 21, no. 1, pp. 25-33, 1985. 


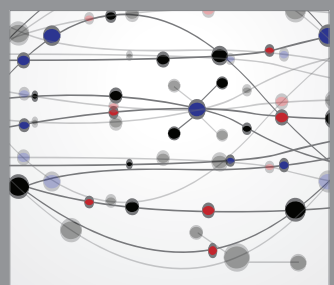

The Scientific World Journal
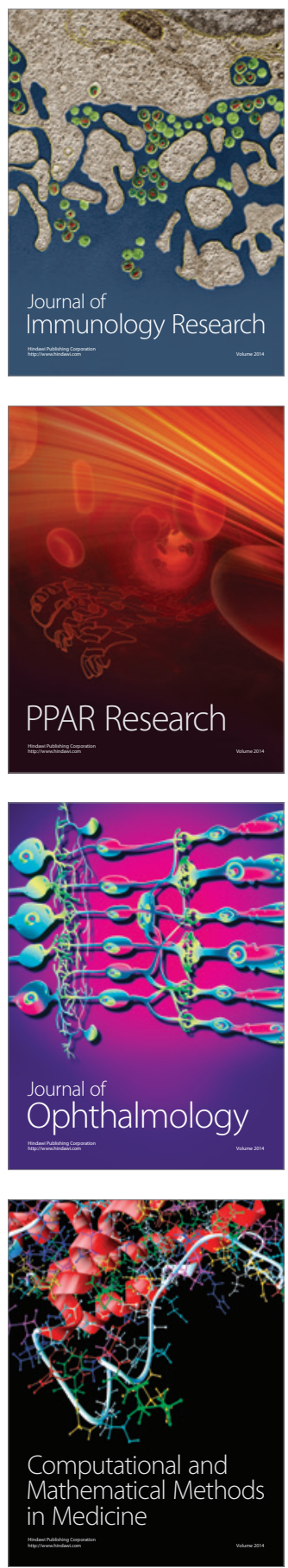

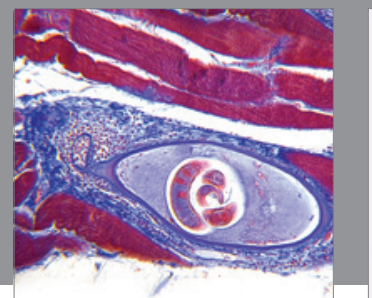

Gastroenterology

Research and Practice
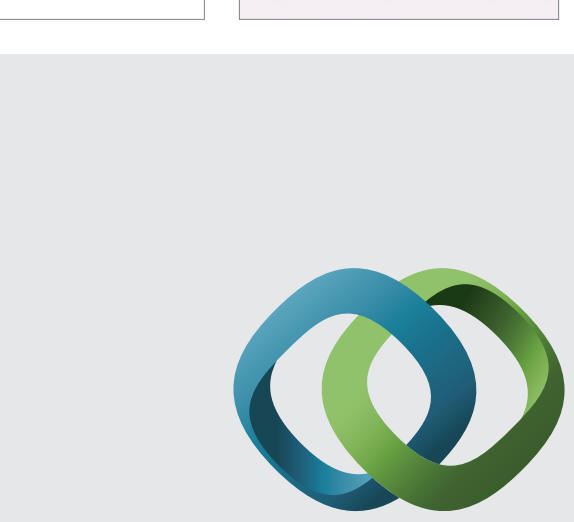

\section{Hindawi}

Submit your manuscripts at

http://www.hindawi.com
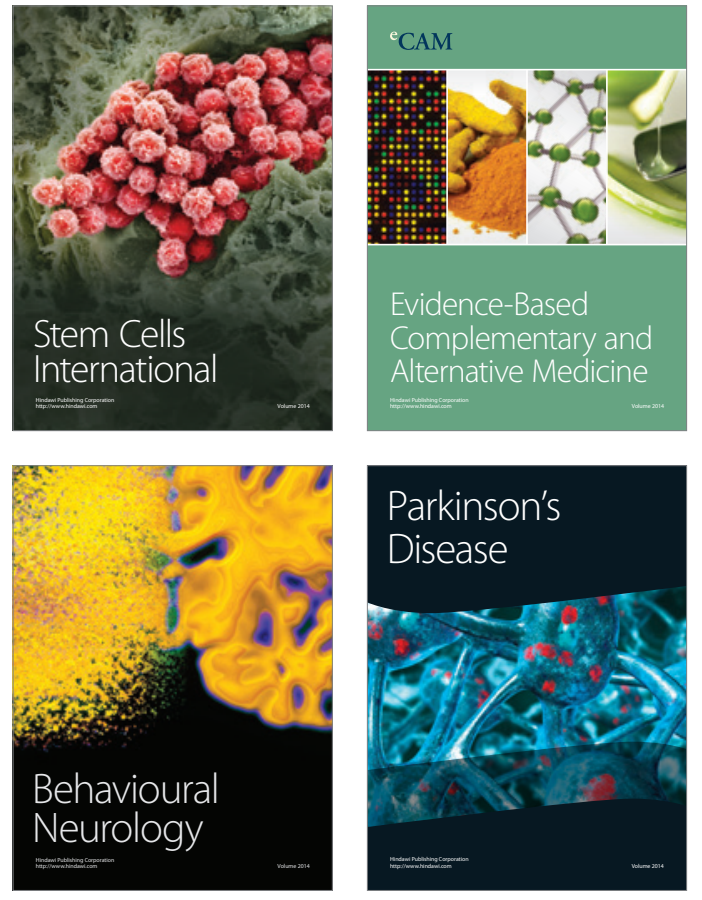
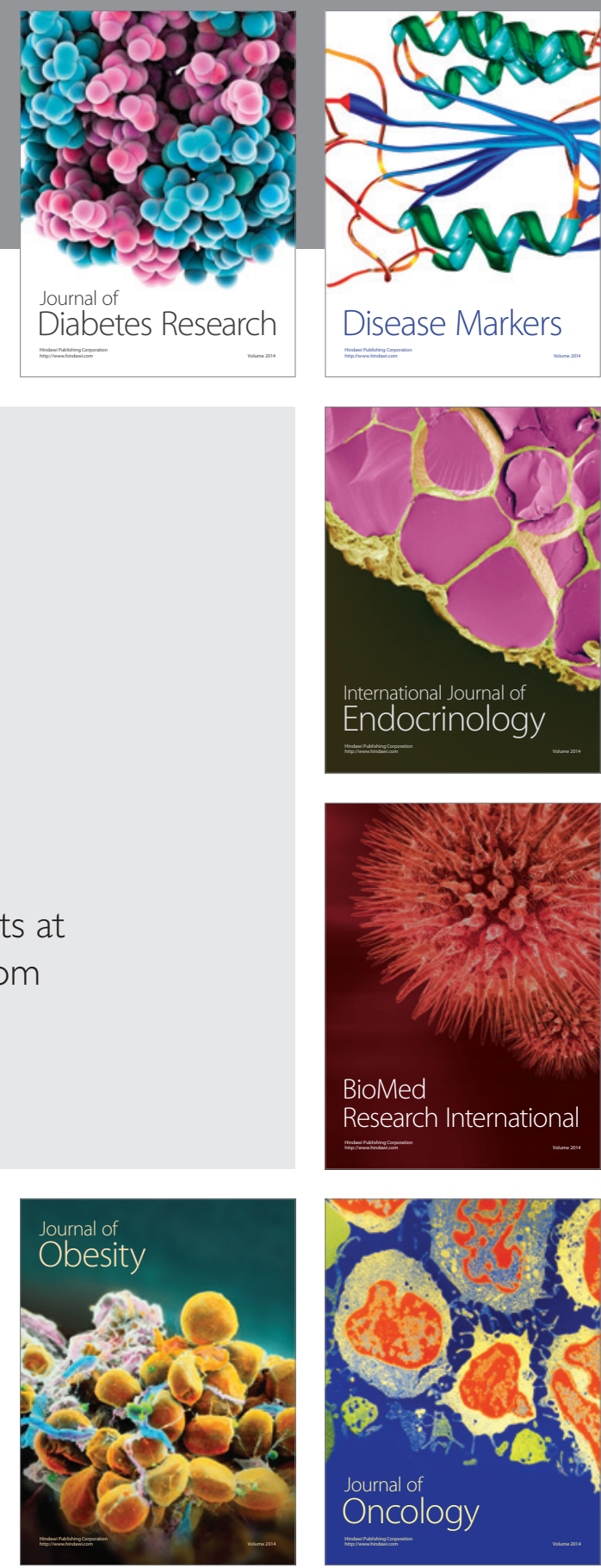

Disease Markers
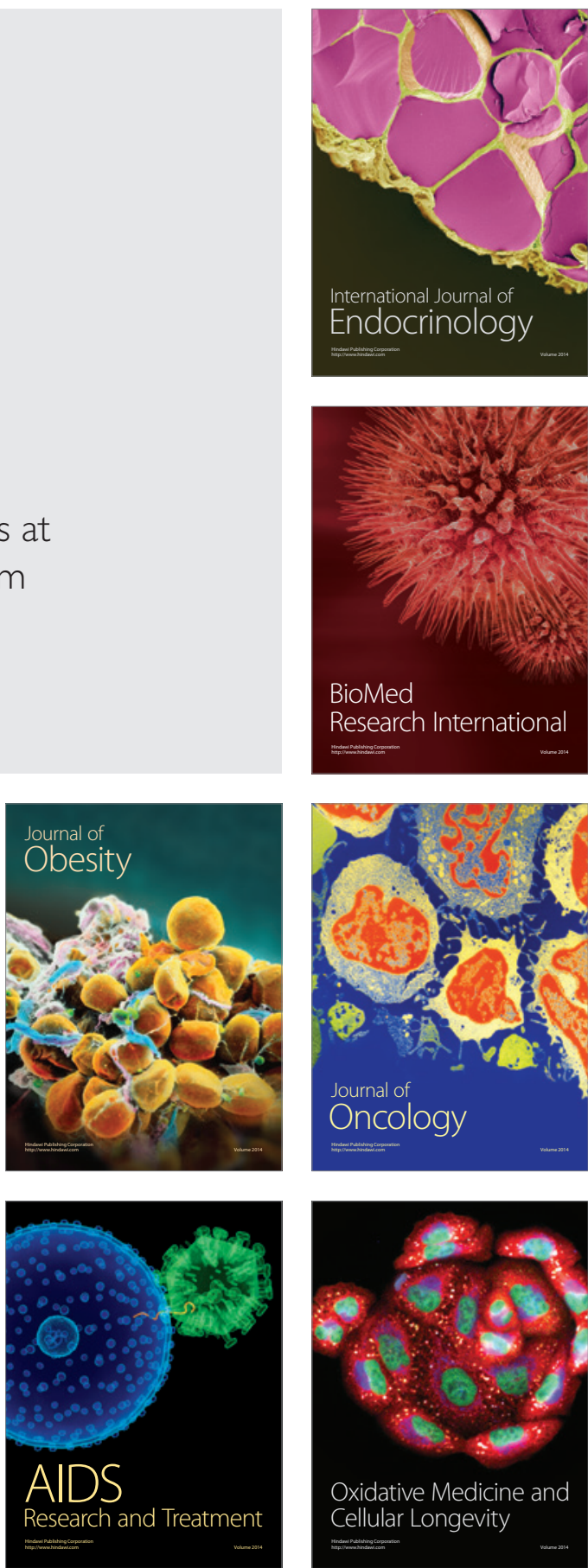